\title{
Patela doble en el plano coronal: reporte de un caso, revisión y clasificación
}

\section{Double patella in the coronal plane: case report, review and classification}

\author{
Michael Hirsch ${ }^{1,2 *}$, Cecilia Huenchullan ${ }^{1}$, Pablo Riedemann ${ }^{3}$ y Jorge Olivares ${ }^{4}$
}

${ }^{1}$ Departamento de Imágenes, Clínica Alemana de Temuco; ${ }^{2}$ Departamento de Especialidades Médicas, Facultad de Medicina, Universidad de La Frontera; ${ }^{3}$ Unidad de Reumatología, Facultad de Medicina, Universidad de La Frontera; ${ }^{4}$ Departamento de Medicina General, Clínica Alemana de Temuco. Temuco, Chile

\section{Resumen}

La patela doble es una afección rara, generalmente no sospechada durante la evaluación clínica. Presentamos el caso de un varón de 64 años que consultó por dolor de rodilla. La radiografía y la ecografía sugirieron una duplicación patelar en el plano coronal que fue confirmada por resonancia magnética (RM). La patela es el hueso sesamoideo de mayor tamaño y puede tener múltiples alteraciones de su desarrollo, que son relativamente frecuentes. Puede tener variaciones en su forma, osificación, posición e hipoplasia, pero la duplicación congénita es un hallazgo poco común en la práctica clínica, especialmente en el plano coronal. La RM es la mejor opción de imagen, ya que su evaluación multiplanar y su alto contraste tisular permite un mejor reconocimiento de una segunda estructura independiente. Revisamos la literatura e ilustramos una clasificación de la patela doble, la cual debe ser considerada entre los diagnósticos diferenciales de patologías congénitas, traumáticas y degenerativas.

Palabras clave: Anomalías congénitas. Patela. Ortopedia. Radiología. Resonancia magnética.

\section{Abstract}

Double patella is a rare condition, usually unsuspected during clinical evaluation. We report the case of a 64-year-old male who consulted for knee pain. The radiograph and ultrasound suggested a double patella in the coronal plane that was confirmed by magnetic resonance imaging (MRI). The patella is the largest sesamoid bone and could have multiple alterations of its development, which are relatively frequent. It can have variations in its ossification shape, position and hypoplasia, but congenital duplication is an uncommon finding in clinical practice, especially in the coronal plane. MRI is the best imaging option because it allows multiplanar evaluation and has a high tissue contrast, which allows better recognition of a second independent structure. We review the literature and illustrate a classification of the double patella, which must be considered among the differential diagnoses of congenital, traumatic and degenerative conditions.

Key words: Congenital abnormalities. Patella. Orthopaedic. Radiology. Magnetic resonance imaging.

Correspondencia:

*Michael Hirsch

E-mail: michael.hirsch@ufrontera.cl
Fecha de recepción: 16-12-2020

Fecha de aceptación: 18-03-2021

DOI: 10.24875/RCHRAD.M21000006
Disponible en internet: 21-09-2021

Rev Chil Radiol. 2021;27(3):154-158 www.resochradi.com 0717-9308 / @ 2021 Sociedad Chilena de Radiología. Publicado por Permanyer. Éste es un artículo open access bajo la licencia CC BY-NC-ND (https://creativecommons.org/licenses/by-nc-nd/4.0/). 


\section{Introducción}

La patela doble es un problema médico infrecuente, rara vez se sospecha durante la evaluación clínica debido al dolor de rodilla y generalmente se advierte en estudios de imágenes. La patela es el hueso sesamoideo de mayor tamaño y puede tener múltiples alteraciones de su desarrollo, que son relativamente frecuentes, pero la duplicación congénita es un hallazgo infrecuente en la práctica clínica, especialmente en el plano coronal ${ }^{1}$. Los estudios de imagen son fundamentales para confirmar la sospecha clínica o son el primer acercamiento a esta patología y, lo más importante, permiten evaluar adecuadamente otros diagnósticos diferenciales. También permiten caracterizar adecuadamente el tipo de duplicación.

Presentamos el caso de una duplicación patelar no sospechada, que fue atendida en consulta externa por dolor en rodilla y pierna. Se realizaron estudios con radiografía, ultrasonido (US) y resonancia magnética (RM), lo que convierte este caso en uno de los pocos reportados con estudio completo de imágenes. Revisamos la literatura, ilustramos una clasificación para esta condición y demostramos la utilidad de la RM en estos casos.

\section{Presentación del caso}

Hombre de 64 años con antecedentes de diabetes mellitus diagnosticada hace 20 años, en tratamiento con insulina, y enfermedad de Parkinson diagnosticada hace nueve años en control y tratamiento. En relación con esta última enfermedad refiere presentar desde hace un par de años dificultades para caminar con pérdida ocasional de equilibrio, por lo que ha tenido varias caídas menores. Consulta por dolor en la pierna derecha y la rodilla de un mes de evolución, sin ningún evento desencadenante evidente. Al examen físico se observó aumento de volumen de la rodilla derecha respecto a la contralateral, sin signos clínicos inflamatorios, con movilidad articular conservada y dolor leve durante la exploración. Se solicita US de rodilla que muestra derrame articular y una masa ósea medial a la patela con hendidura que la separaba de esta (Fig. 1). Inicialmente se consideró que podría corresponder a osificación o secuelas de una antigua fractura patelar. Se realizó una radiografía complementaria (Fig. 2) y ante la sospecha de duplicación patelar se sugirió un estudio de RM.

En la RM se confirmó la presencia de una patela accesoria de tamaño similar a la nativa, localizada

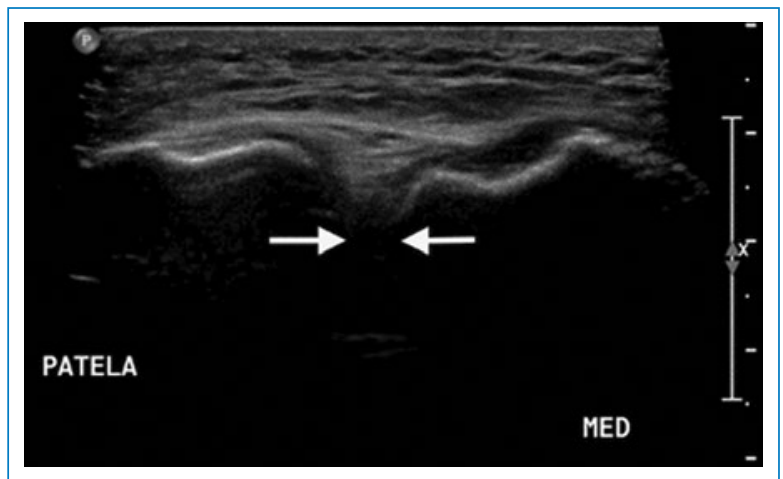

Figura 1. Ultrasonido de la rodilla en el plano axial mostrando ambas patelas y el plano articular entre ellas (flechas).

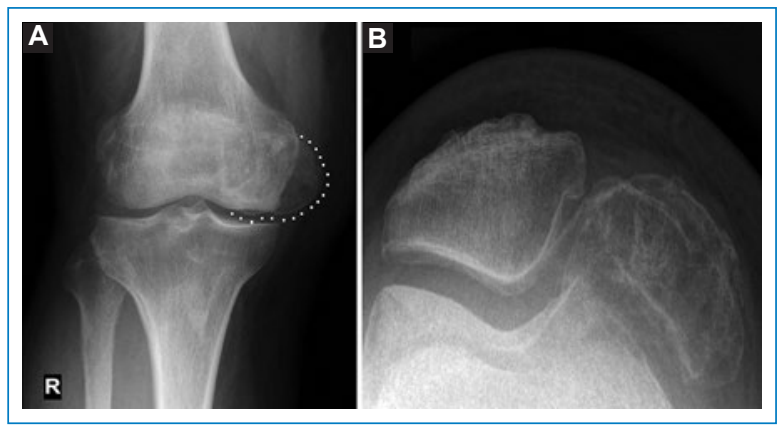

Figura 2. A: radiografía de rodilla antero-posterior y B: axial mostrando una rótula accesoria localizada medial al surco troclear (línea punteada), además de cambios articulares degenerativos.

medial al surco troclear y cubierta por cartílago en su cara posterior. Además se articulaba con el fémur y la rótula nativa, con cambios degenerativos en esta última articulación, asociados a un aumento de la señal de la médula ósea en secuencia ponderada en densidad protónica con saturación grasa (PDw-FS). También se detectaron bandas hipointensas compatibles con expansiones retinaculares en ambos lados. Parte del tendón del vasto medial se insertaba en el polo superior, presentando un delgado tendón patelar distal propio, que se insertaba medial a la tuberosidad anterior de la tibia. Ambas patelas compartían el mismo espacio articular, lo que era notorio gracias al derrame articular presente. También se observó pinzamiento de una plica patelar medial entre la patela accesoria y el cóndilo femoral medial (Fig. 3). Dentro de los otros hallazgos destacaba fractura subcondral por insuficiencia en el sitio de carga del cóndilo femoral medial, asociado a aumento de señal de la médula ósea en las secuencias PDw-FS, rotura del menisco medial, 

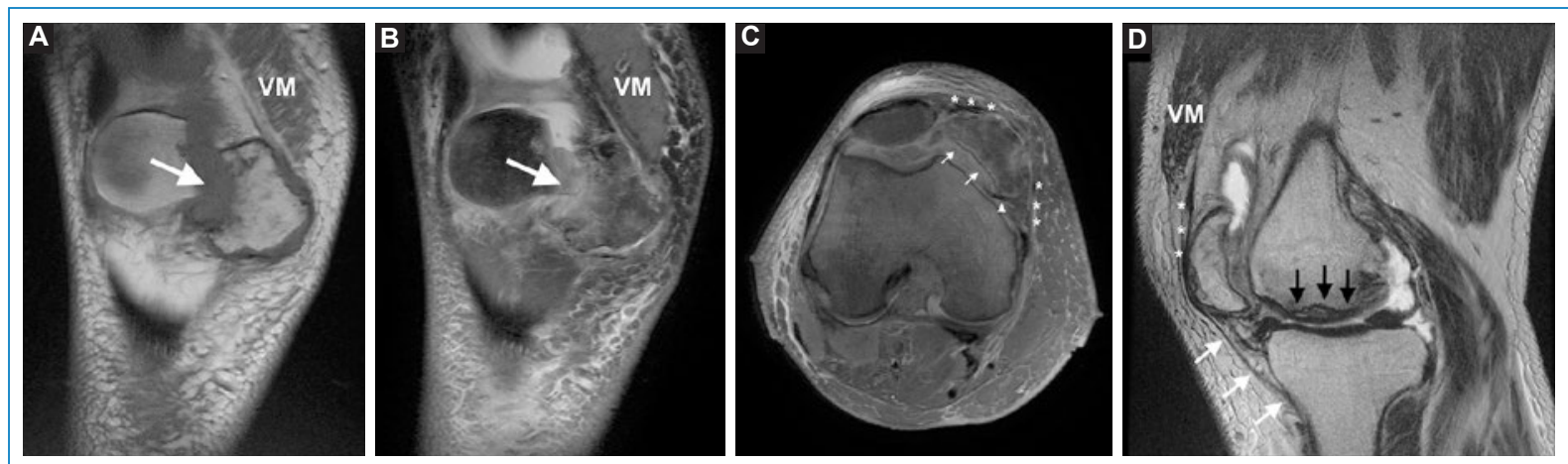

Figura 3. A: imágenes de resonancia magnética (RM) coronales en secuencia ponderada en densidad protónica con saturación grasa (PDw-FS) y B: T1w. Se identifican fibras del músculo vasto medial (VM) formando un tendón que se inserta en la patela accesoria, alteración en la señal de la médula ósea asociada a cambios degenerativos en la articulación entre las ambas patelas (flecha), derrame articular y edema subcutáneo. C: imagen de RM axial PDw-FS que muestra la superficie condral en la cara posterior de la patela accesoria (flechas), retináculo en ambos lados (asteriscos) y una plica patelar medial entre la patela y el cóndilo medial (punta de flecha). D: imagen de RM sagital T2w a nivel de la patela accesoria que muestra el tendón superior (asteriscos) que se origina en el VM y el tendón inferior (flechas blancas), que se inserta en el aspecto medial de la tuberosidad tibial anterior, además de una fractura subcondral en el cóndilo medial (negro flechas).

cambios degenerativos condrales tricompartimentales, moderado derrame articular y edema subcutáneo difuso. El paciente fue derivado al traumatólogo, sin acudir al seguimiento.

\section{Discusión}

La patela es el hueso sesamoideo más grande del cuerpo humano y forma parte de la articulación de la rodilla. Su desarrollo embriológico se inicia a partir de un núcleo cartilaginoso en el primer trimestre de vida intrauterina y continúa con su osificación endocondral, que puede ser recién evidente desde los tres hasta los seis años, completando su desarrollo hasta los 18 años, proceso que depende de uno a tres centros de osificación. Estos centros de osificación son la causa de múltiples alteraciones de su desarrollo, dando lugar a variantes de normalidad y entidades patológicas ${ }^{2}$.

Las anomalías del desarrollo son relativamente frecuentes. En orden descendente de frecuencia encontramos variaciones en su osificación (patela bipartita, tripartita), forma, posición e hipoplasia. Sin embargo la duplicación de la patela es extremadamente rara y se considera una malformación congénita ${ }^{1}$, aunque en algunos casos se proponen anomalías del desarrollo influenciadas por elementos externos ${ }^{3}$.

Se han descrito tres tipos de patela doble según su disposición espacial (Fig. 4): horizontal, referida al plano de separación entre las dos patelas, una superior a la otra; frontal, una anterior a la otra, también descrito como una "patela de doble capa», y el tercer tipo en el plano coronal, una al lado de la otra. En la clasificación original de Ficat (1970) solo había dos tipos, y Gasco, et al., (1987) informaron por primera vez de la del tercer tipo ${ }^{4}$.

La duplicación horizontal se describió por primera vez en 1902 y posteriormente en $1925^{5,6}$, apareciendo más tarde una serie de casos en la literatura, siendo la más frecuente de todas las duplicaciones ${ }^{1}$. Existen algunos casos de patologías adquiridas que simulan este tipo de duplicación patelar. Estos incluyen causas traumáticas como fracturas avulsivas de los polos de la patela o de la inserción tibial del tendón patelar, y la enfermedad de Sinding-Larsen-Johansson ${ }^{3,7,8}$.

Las primeras publicaciones de duplicación frontal datan de $1925^{9,10}$. Posteriormente, hubo una serie de publicaciones sobre este tipo de patela doble en el contexto de la displasia epifisaria múltiple, considerada por algunos como patognomónica de esta enfermedad, particularmente la variante autosómica recesiva ${ }^{11}$. También existen casos de patología adquirida que simulan este tipo de patela, como la osteocondromatosis sinovial ${ }^{12}$.

El primer caso de duplicación coronal publicado fue el de un niño de seis años que consultó por una deformidad progresiva de la rodilla izquierda, sin dolor ni 


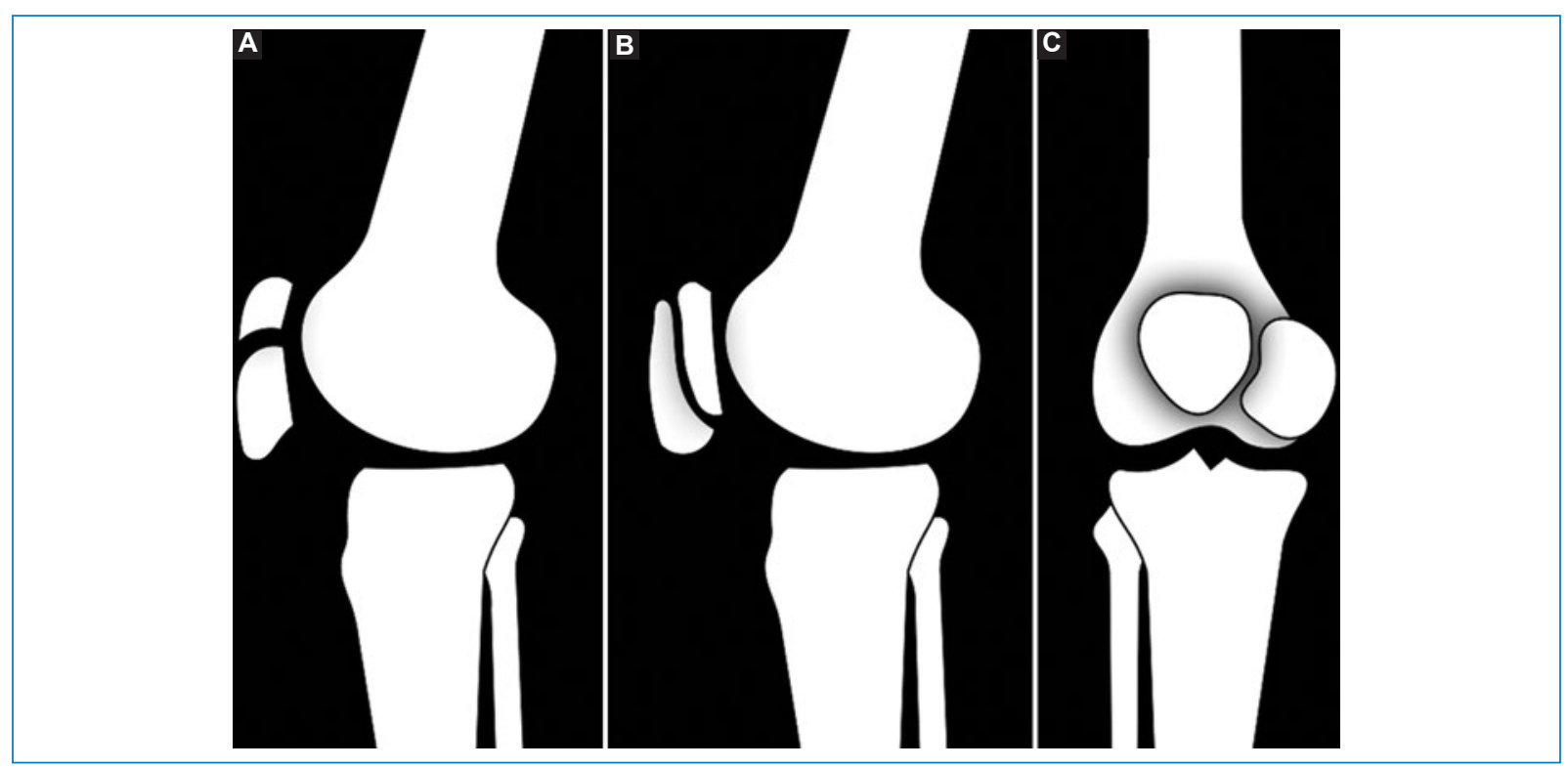

Figura 4. Dibujo que muestra los tres tipos de duplicación patelar: A: horizontal, B: frontal o «rótula de doble capa» y C: coronal.

limitaciones funcionales ${ }^{4}$. Al examen físico la rodilla presentaba contornos anormales, palpándose una doble patela, entre las cuales había un surco, permitiendo movilidad independiente entre ambas con el cuádriceps relajado. El hueso más grande estaba situado en la cara lateral de la rodilla y el más pequeño en situación intercondílea. Realizaron una tomografía computarizada para confirmar los hallazgos clínicos y radiográficos, mostrando que cada patela tenía su propia expansión aponeurótica y tendón patelar. EI paciente fue tratado mediante escisión de la patela medial más pequeña; se conservó su tendón y se centró la patela lateral en su parte proximal mediante la técnica de Insall, y su tendón patelar se trasladó medialmente mediante la técnica de Roux-Goldthwait. La recuperación fue favorable, alcanzando la función articular normal a los dos años.

La segunda publicación de duplicación patelar coronal corresponde al caso de un paciente de 74 años con antecedente de genu valgo izquierdo progresivo, diagnosticado a los seis años y tratado ortopédicamente ${ }^{1}$. El cuadro clínico consistía en gonalgia, claudicación, rigidez matinal e impotencia funcional. Al examen físico presentaba un aumento de volumen redondeado, de consistencia dura, indolora, con ligera movilidad y ubicado medial a la patela. Destaca en este estudio la utilización de RM, que reveló la presencia de articulaciones entre las dos patelas y entre estas y el fémur, cobertura condral en la superficie posterior de la patela accesoria y elementos de sostén como retináculo, tendón cuadricipital cubriendo ambas patelas y tendón patelar fino distal a la patela accesoria. Estos elementos son similares a los exhibidos en nuestro reporte. En nuestro caso destaca la presencia de patologías concomitantes como la fractura subcondral del cóndilo femoral medial, con extenso edema óseo y rotura meniscal, las cuales explican gran parte de la sintomatología por la que consultó el paciente.

La duplicación congénita de la patela, en cualquiera de sus planos, es un hallazgo infrecuente en la práctica clínica, sobre todo en el plano coronal. En la literatura internacional solo existen dos casos reportados en el plano coronal en nuestro conocimiento previo a este caso.

La presentación clínica de las duplicaciones es inespecífica, sobre todo si la presentación es única y no formando parte de una enfermedad sistémica. Puede ser asintomática o manifestarse con gonalgia, deformidad ósea, limitación funcional y bloqueo. Por esta razón, los estudios de imagen son fundamentales para diagnosticar y caracterizar esta condición y para excluir otros diagnósticos diferenciales, principalmente anomalías del desarrollo y traumáticas ${ }^{13}$. La mayor contribución para el estudio y caracterización de esta condición la realiza la RM, que gracias a su evaluación multiplanar y con alto contraste entre los tejidos 
permite reconocer una segunda estructura conformando un sistema osteoarticular, tendíneo y ligamentoso independiente ${ }^{14}$. Sin embargo, como en nuestro caso, es posible sospechar esta condición con el US y confirmarlo con la radiografía.

\section{Conclusión}

La duplicación patelar es una condición poco frecuente, sin elementos clínicos específicos. El conocimiento de esta patología asociado a un alto índice de sospecha y un adecuado estudio de imagen permiten un diagnóstico preciso, que evita tratamientos inadecuados.

\section{Financiamiento}

Los autores declaran no haber recibido financiamiento para este estudio.

\section{Conflicto de intereses}

Los autores declaran que no existen conflictos de intereses en relación con el contenido de este trabajo de investigación.

\section{Responsabilidades éticas}

Protección de personas y animales. Los autores declaran que para esta investigación no se han realizado experimentos en seres humanos ni en animales.

Confidencialidad de los datos. Los autores declaran que en este artículo no aparecen datos de pacientes.

Derecho a la privacidad y consentimiento informado. Los autores declaran que en este artículo no aparecen datos de pacientes.

\section{Bibliografía}

1. Visconti D, Della Sala SW, Bianchini G, Manera V. Double congenita patella: case report and review of the literature. Eur Radiol. 1996;6:566-9.

2. Ogden JA. Radiology of postnatal skeletal development. X. Patella and tibial tuberosity. Skeletal Radiol. 1984;11:246-57.

3. Hägglund $\mathrm{G}$, Pettersson $\mathrm{H}$. A case of bilateral duplication of the patella. Acta Orthop Scand. 1989;60:725-7.

4. Gasco J, del Pino JM, Gomar-Sancho F. Double patella. A case of duplication in the coronal plane. J Bone Joint Surg Br. 1987;69:602-3.

5. Joachimsthal. Über struktur, lage und anomalien der menschlichen kniescheibe. Arch Klin Chir. 1902;67:342-68.

6. Petty MJ. Two cases of abnormal patellae. Br J Surg. 1925;12:799-800

7. Cipolla M, Cerullo G, Franco V, Gianni E, Puddu G. The double patella syndrome. Knee Surg Sports Traumatol Arthrosc. 1995;3:21-5.

8. Yeung E, Ireland J. An unusual double patella: a case report. Knee. 2004;11:129-31.

9. Büttner G. Zür ätiologie und pathogenese der perthesschen krankheit (Zugleich ein Fall von Patella tripartita). Arch f klin Chir. 1925;136:703.

10. Hänisch F. Bisher nicht beschriebene Verdoppelungsform der Patella. Fortschr Röntgenstr. 1925;33:678-9.

11. Anthony S, Munk R, Skakun W, Masini M. Multiple epiphyseal dysplasia. J Am Acad Orthop Surg. 2015;23:164-72.

12. Kajikawa $Y$, Arai $Y$, Takamiya H, Higuchi T, Mori G, Morisaki S, et al. A double patella-like condition secondary to synovial osteochondromatosis. Sports Med Arthrosc Rehabil Ther Technol. 2012:4:31.

13. Kumar K, Knight DJ. Sleeve fracture of the superior pole of patella: a case report. Knee Surg Sports Traumatol Arthrosc. 2005;13:299-301.

14. Tyler $P$, Datir A, Saifuddin A. Magnetic resonance imaging of anatomical variations in the knee. Part 2: miscellaneous. Skeletal Radiol. 2010;39:1175-86. 